\title{
Polymer Supported Schiff Base Iron Complex for Epoxidation of Trans-stilbene
}

\author{
N. Nath, H. C. Pradhan, T. Maharana, and A. K. Sutar
}

\begin{abstract}
In the present investigation, the novel recyclable polystyrene anchored iron complex supported by -ONN Schiff base is synthesized. This polymer anchored iron complex is prepared by the reactions of metal solution with one molar equivalent of polystrene supported Schiff-base ligands in methanol under nitrogen atmosphere. In contrast with other polymer-supported catalysts, the greatest advantage of this catalyst system was that the cost of the catalyst was remarkably low and recycled up to six times, due to the easily accessible materials and the simple synthetic route. The higher efficiency of complexation of metal ions on the polymer anchored Schiff base than unsupported analogue was another advantages of this catalyst system. The structural study reveal that iron(III) complex is octahedral in geometry. The catalytic activities of polystyrene supported iron complex toward the epoxidation of trans-Stilbene is investigated. Experimental results indicate that the reactivity of iron complex is dramatically affected by the polymer support and the rate of trans-Stilbene conversion was $4.27 \times 10^{-7}$ moledm $^{-3} \mathrm{~s}^{-1}$ and obeys first order kinetics. The efficiency of supported catalysts remained almost constant upto six recycles.
\end{abstract}

Index Terms-Oxidation, polymers, catalysis, iron, trans-stilbene.

\section{INTRODUCTION}

Since the beginning of concept of Schiff base chemistry, it has been the constant challenge for scientists to search and find new Schiff base metal complexes [1] because of the wide applications in catalysis, oxygen storage devices [2] and also present antitumoral, antiviral, and antibacterial activity [3] and are used as mimetic systems for enzyme models. [4] Metal complexes of Schiff bases were used as catalyst for the organic transformations such as oxidation [5], [6], olefin epoxidation [7], [8], polymerization of ethylene [9] even though homogeneous catalysts suffer from drawback of poor catalyst recovery and product separation [10]-[12]. However, it was found that the homogeneous Schiff base catalytic systems have two major disadvantages: 1) the lack of control of product, which causes the reactor fouling and 2) the limitation of its use in solution process. In order to overcome to this limitation and combine the advantages of homogeneous and heterogeneous catalyst, homogeneous catalysts have been immobilized in several heterogeneous organic and inorganic supports [13], [14]. In addition to inorganic supports, polymeric supports have gained interest

Manuscript received July 15, 2016; revised September 20, 2016.

A. K. Sutar is with Catalysis Research Lab, Department of Chemistry, Ravenshaw University, Cuttack-3, Odisha, India (e-mail: dralekhasutar@gmail.com).

T. Maharana is with Department of Chemistry, National Institute of Technology, Raipur, India (e-mail: mtungabidya@gmail.com). because they are inert, nontoxic, nonvolatile, insoluble and recyclable [15], [16]. Among the polymeric supports, chloromethylated polystyrene crosslinked with divinylbenzene is one of the most widely used supports [17] Recently, epoxidation of alkenes is one of the most widely studied reactions in organic chemistry, as the product epoxides, are used widely as intermediates in organic synthesis, pharmaceuticals as well as polymer production. They are used to provide industrially important products like surfactants, detergents, antistatic agents and corrosion protection agents, lubricating oils, textiles and cosmetics and it also play a key role in the formation of various biologically active compounds [18].

Epoxidation of stilbene using various chemical reagents such as, hydrogen peroxide, permanganate, molecular oxygen and ozone, are widely used [1]. The use of hydrogen peroxide has the advantage of producing oxygen and can be used to augment biological degradation [6]. Besides, the adoption of $\mathrm{H}_{2} \mathrm{O}_{2}$ as an alternative of current industrial oxidation processes offers environmental advantages, some of which are: a) replacement of stoichiometric metal oxidants; b) replacement of halogens; c) replacement or reduction of solvent usage; and d) avoidance of salt by-products. Hydrogen peroxide works either alone or with a catalyst. But with catalyst, it gives better results. Iron is the most common homogeneous catalyst for hydrogen peroxide [6].

This paper reports the synthesis and characterization of new polymer supported Schiff base complexes of iron(III) and their catalytic activity towards epoxidation of trans-Stilbene, using $\mathrm{H}_{2} \mathrm{O}_{2}$ as oxidant.

\section{MATERIALS}

Divinyl benzene cross-linked chloromethylated polystyrene beads (with chlorine content $2.5-4 \mathrm{mmol} / \mathrm{g}$ ) was obtained from "Ion Exchange India Ltd." (India). $\mathrm{FeCl}_{3}$, trans-Stilbene (purity 95.5\%), $\mathrm{H}_{2} \mathrm{O}_{2} \quad(30.0$ wt \%), ethylenediamine and 2-hydroxy -1-napthaldehyde were procured form "Merck" (India). Other chemicals and solvents were of analytical grade $(>99.0 \mathrm{wt} \%)$.

Characterization of the Polymer Supported Schiff Base and Its Iron Complex

IR spectra of polymer supported Schiff base and its iron complexes were recorded on $\mathrm{KBr}$ pellet using Perkin-Elmer 1600 FTIR Spectrophotometer. The electronic spectra of Schiff base and its iron complexes were recorded with Shimadzu 1601 PC UV-Vis Spectrophotometer by using sample mull in a cuvette. Thermo gravimetric analysis (TGA) of Schiff base and its ion complex was carried out using Perkin-Elmer Pyris, Diamond Thermal Analyzer under 
nitrogen atmosphere at a heating rate of $10^{\circ} \mathrm{C} \mathrm{min}^{-1}$. The loading of iron ion on Schiff base was determined by analyzing the loading solution with Perkin-Elmer 3100 Atomic Absorption Spectrometer at $\lambda_{\max }$ of corresponding metal ions. The ${ }^{1} \mathrm{H}-\mathrm{NMR}$ spectra of Schiff base and its metal complexes were recorded on an FT-NMR-Brucker $300 \mathrm{MHz}$ Spectrometer using DMSO- $\mathrm{d}^{6}$ as a solvent and tetramethylsilane (TMS) as an internal reference. The magnetic moment $(\mu)$ of metal complexes was measured using Vibrating Sample Magnetometer-155. The molecular weight of Schiff base was determined using a Vapor Pressure Osmometer (Merck VAPRO 5600, Germany).

\section{RESULTS AND DISCUSSION}

The oxidation of stilbene with polymer-anchored Schiff base complexes of iron ion was found to be higher and more selective than those with unsupported Schiff base complexes of this metal ion. These results clearly indicate that a polymer support plays a positive role in modifying the activity of metal-ion complexes, as reported in the literature [1]. The activity of a catalyst on a support is increased, provided that the nature of the catalyst is not destroyed and the support is able to provide a liquid-phase environment as found with polymer supports; hence, the properties of polymer supports influence the activity of anchored catalysts. Although the amount of loaded metal ions influences the activity of a supported catalyst, the activity of a supported catalyst is also influenced by leaching of the catalyst from the polymer support [1]. The leaching of catalysts from the polymer-anchored complexes was determined by an analysis of the recycled catalyst ash for loaded metal ions with an atomic absorption spectrometer, and it was found to be insignificant for polymer-supported catalysts recycled up to six times. The analysis of the recycled catalysts also indicated that the supported catalysts were stable and maintained their catalytic activity in the oxidation of phenol without leaching of metal ions as found with physically anchored catalysts [8]. The thermal stability of the supported Schiff base and iron catalysts was also analyzed for their applications in high-temperature reactions and to provide proof for the complexation of metal ions with a polymer-anchored Schiff base. The TGA of polymer supported Schiff base showed a weight loss of $40.4 \mathrm{wt} \%$ at $500{ }^{\circ} \mathrm{C}$, but its iron(III showed a weight loss of 25.2 at same temperature, which was clear indication that iron(III) ion complexes were more stable [7] In addition to thermal analysis, the polymer-supported metal complexes of Schiff base were also characterized by IR and UV techniques to provide a proof for the complexation of metal ions and to decide the structures and geometries of metal complexes on the basis of elemental analysis and magnetic properties of metal complexes.

Excellent selectivity of epoxidation for trans-Stilbene was obtained. The immobilized polymer anchored catalysts can be reused for more than six times without any significant loss in their activities. The polymer supported Schiff base ligand(L) has been synthesized (Scheme 1) by refluxing $1 \mathrm{gm}$ of chloromethylated poly(styrene-divinyl benzene) with ethylenediamine in THF at room temperature for $48 \mathrm{~h}$. The white beads thus obtained were washed off with demonized water followed by methanol and dried in vacuum. Thus the dried beads were reacted with 2-hydroxy-1-napthaldehyde in toluene and refluxed for $24 \mathrm{~h}$. The product thus formed was washed with toluene followed by methanol and dried under vacuum. The FeL Schiff base complex was prepared by the reaction of $\mathrm{FeCl}_{3}$ with $\mathrm{L}$ (Scheme 1).

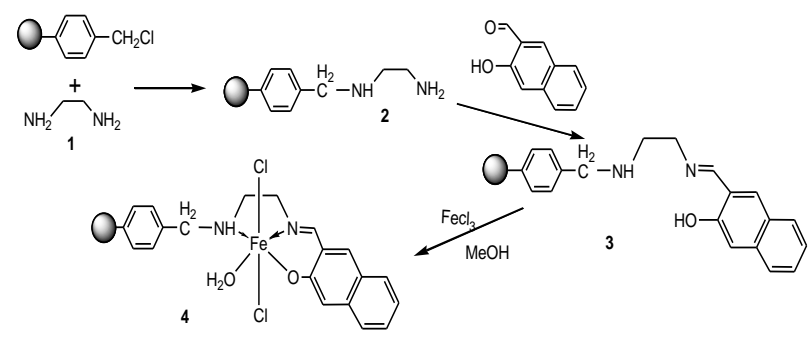

Scheme 1. Preparation of polymer-anchored schiff base catalyst.

The FTIR spectra conforms the attachment of polymer support. The band at $1261 \mathrm{~cm}^{-1}$ is due to the presence of $\mathrm{C}-\mathrm{Cl}$ in pure chloro methylated polystyrene 1) The intensity of this $\mathrm{C}-\mathrm{Cl}$ band decreased in the polymer supported metal complex, which is the clear indication of attachment of polymer support. The band at $3432 \mathrm{~cm}^{-1}$ represent to $\mathrm{N}-\mathrm{H}$ stretching (secondary amine) vibration of polymer-anchored ethylenediamine 2) and the band at $1629 \mathrm{~cm}^{-1}$ due to $\mathrm{N}-\mathrm{H}$ bending vibration of primary amine, which reduced in intensity when reacted with 2-Hydroxy-1-napthaldehyde. The stretching vibration of azomethine group (C-N) at $1622 \mathrm{~cm}^{-1}$ of polymer-anchored Schiff base ligand 3 ) was shifted to the lower frequency at $1610 \mathrm{~cm}^{-1}$ in the iron complexe 4) This gives the clear indication that Schiff base is attached to the iron through the azomethine nitrogen. The appearance of new absorption band at $414 \mathrm{~cm}^{-1}$ and $544 \mathrm{~cm}^{-1}$ in polymer-anchored Schiff base iron complex is due to the formation of $\mathrm{Fe}-\mathrm{N}$ bond and $\mathrm{Fe}-\mathrm{O}$ bond, respectively [19]. The magnetic moment (5.08 B.M) of iron complex indicates a high-spin octahedral geometry [20], [21]. The complex exhibit ligand to metal charge transfer(LMCT) transitions as well as low intensity spin forbidden $\mathrm{d}-\mathrm{d}$ transition, as high-spin Fe(III) complex $\left(d^{5}\right)$ is oxidizing in nature. The electronic spectrum also conform the structure. Three broad bands in the range 245-270nm, 318-343nm and $463-492 \mathrm{~nm}$ were observed. And among these, the very low intensity bands at $463-492 \mathrm{~nm}$ may be represent to ${ }^{6} \mathrm{~A}_{1 \mathrm{~g}} \rightarrow{ }^{4} \mathrm{~A}_{1 \mathrm{~g}}(\mathrm{G})$ and ${ }^{6} \mathrm{~A}_{1 \mathrm{~g}} \rightarrow{ }^{4} \mathrm{~T}_{2 \mathrm{~g}}(\mathrm{G})$ transitions in octahedral symmetry of Fe(III) complex [22], [23]. The intensities of the bands in the spectrum are affected possibly due to the low loading of the $\mathrm{Fe}$ (III) complex to polymer support. The catalytic activity of polymer-anchored Fe(III) Schiff base complex was tested in epoxidation of trans-Stilbene as a model substrate using different solvents at $50^{\circ} \mathrm{C}$ (Table I).

TABLE I: EPOXIDATION OF TRANS-STILBENE CATALYZED BY IRON COMPLEX $4^{\mathrm{a}}$

\begin{tabular}{ccc}
\hline Solvent & Time(h) & Conversion (\%) \\
\hline $\mathrm{CH}_{3} \mathrm{CN}$ & 6.5 & 70 \\
$\mathrm{MeOH}$ & 6.5 & 54 \\
$\mathrm{CH}_{2} \mathrm{Cl}_{2}$ & 6.5 & 50 \\
\hline${ }^{\mathrm{a}}$ Reaction conditions: $(10 \mathrm{~mL})$ solvent,$(5 \mathrm{mmol})$ trans-Stilbene, $(10 \mathrm{mmol})$
\end{tabular}

${ }^{\text {a }}$ Reaction conditions: (10mL) solvent, $(5 \mathrm{mmol})$ trans-Stilbene, $(10 \mathrm{mmol})$ oxidant $\left(\mathrm{H}_{2} \mathrm{O}_{2}\right)$ and $(0.05 \mathrm{gm})$ catalyst. 
TABLE II: EFFICIENCY OF RECYCLED SUPPORTED CATALYSTS IN EPOXIDATION OF TRANS-STILBENE

\begin{tabular}{c|c|c|c|c|c|c}
\hline \multicolumn{2}{c}{} & \multicolumn{5}{|c}{ Recycle number } \\
\cline { 3 - 7 } \multicolumn{2}{c|}{} & 0 & 2 & 4 & 6 & 8 \\
\hline $\begin{array}{c}\text { Supported Iron } \\
\text { Complex }\end{array}$ & Conversion & 69.6 & 67.3 & 60.2 & 55.6 & 34.4 \\
\cline { 3 - 7 } & Selectivity & 89.9 & 90.3 & 88.2 & 86.2 & 81.9 \\
\hline
\end{tabular}

trans -Stilbene $=5 \mathrm{mmol}$, oxidant $\left(\mathrm{H}_{2} \mathrm{O}_{2}\right)=10 \mathrm{mmol}$ and catalyst $=0.05 \mathrm{gm}$, Temp. $=50{ }^{0} \mathrm{C} . \mathrm{CH}_{3} \mathrm{CN}=10.0 \mathrm{~mL}$.

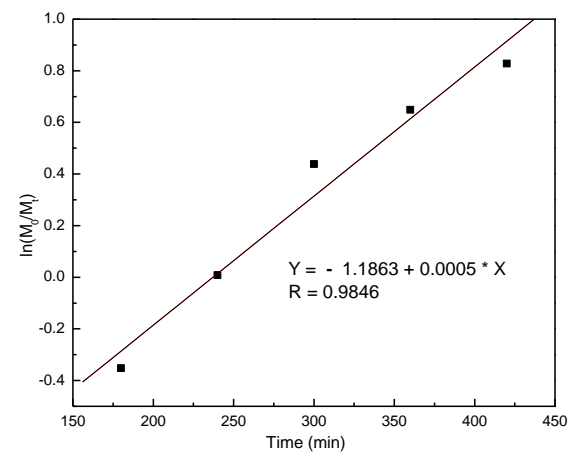

Fig. 1. Semilogarithimic plots of trans-Stilbene conversion in time.

This result shows that in presence of $\mathrm{CH}_{3} \mathrm{CN}$, higher epoxidation yield was observed as compared to $\mathrm{MeOH}$ and $\mathrm{CH}_{2} \mathrm{Cl}_{2}$. This is because the dielectric constant of $\mathrm{CH}_{3} \mathrm{CN}$ ( $\varepsilon=37.5)$ is high as compared to $\mathrm{MeOH}(\varepsilon=32.5)$ and $\mathrm{CH}_{2} \mathrm{Cl}_{2}$ $(\varepsilon=8.9)$.This may be due to the polarity of solvent and the better solubility of the oxidant and substrate in the solvent [19]. The polymer support has facilitated the decomposition of intermediates; hence, \% conversion of trans-Stilbene was more with polymer-supported metal complexes in comparison to free iron complex. The conversion of trans-Stilbene by iron catalyst was high at $300 \mathrm{~min}$ and then after the conversion became almost constant due to substantial decrease in the concentration of oxidant and substrate in the reaction mixture. The amount of trans-Stilbene oxidized with $\mathrm{H}_{2} \mathrm{O}_{2}$ was almost equal to the sum of amount of trans-Stilbene epoxide and benzaldehyde produced, which indicates the formation of other reaction products are almost none. However, the reaction showed high selectivity for trans-Stilbene epoxide as determined from the area under the GC-chromatograms. The supported catalyst was recycled and also further evaluated for their catalytic activity after their applications in epoxidation reaction. The efficiency of supported catalysts remained almost constant upto six recycles and further there is significant decrease (Table II) which may be due to either decomposition of the catalyst in the reaction media or their extraction to the organic solvent during product isolation. [24] The product selectivity for epoxide remained unaffected on using recycled catalysts, which was an indication for the structural stability of iron complex on polymer support as confirmed by comparing IR spectra of recycled catalysts with IR spectra of freshly prepared catalysts. The rate of trans-Stilbene conversion was $4.27 \times 10^{-7}$ mole $\mathrm{dm}^{-3} \mathrm{~s}^{-1}$ in the presence of polymer-supported iron Schiff base complex. We have performed kinetic studies for the trans-Stilbene epoxidation using iron catalyst in the presence of $\mathrm{H}_{2} \mathrm{O}_{2}$. The results are depicted in Fig. 1. This plot (Fig. 1) implies that the epoxidation reaction obeys first order kinetics. There is complete absence of induction period. The $\ln [\mathrm{M}]_{\mathrm{o}} /[\mathrm{M}]_{\mathrm{t}} \mathrm{vs}$ time plots is linear. The values of the apparent rate constant $\left(\mathrm{k}_{\mathrm{app}}\right)$ may be calculated from the slope of these plots. The value of $\mathrm{k}_{\text {app }}$ for trans-Stilbene epoxidation in the presence of $\mathrm{H}_{2} \mathrm{O}_{2}$ was found to be $0.0005 \mathrm{~h}^{-1}$. It was also observed that when oxidant was changed to TBHP, the conversion was low $(63 \%)$ at the same condition. This may be due to immiscible character TBHP in comparison to $\mathrm{H}_{2} \mathrm{O}_{2}$ with the substrate.

\section{CONCLUSIONS}

The simple preparation procedure for polymer anchored $\mathrm{Fe}$ Schiff base complex on polystyrene support has been reported. The catalytic activity towards epoxidation of trans- Stilbene has been tested for complex $\mathbf{4}$ and found highly active and selective catalyst. The epoxidation of trans-Stilbene showed high selectivity for epoxide formation. The complex $\mathbf{4}$ is reusable since it withstand up to six recycling without any loss in their activity.

\section{ACKNOWLEDGMENT}

The authors are thankful to DST \& CSIR, New Delhi, India for funding. The authors are also grateful to Ravenshaw University and National Institute of Technology, Raipur for providing research facilities.

\section{REFERENCES}

[1] K. C. Gupta, A. K. Sutar, and C-C Lin, Coord Chem Rev, vol. 253, p. 1926, 2009.

[2] N. Chantarasiri, T. Tuntulani, P. Tongraung, R. SeangprasertkitMagee, and W. Wannatong, Eur Poly J, vol. 36, p. 695, 2000.

[3] R. Pignatello, A. Panicol, P. Mazzone, M. Pinizzotto, A. Garozzo, and P. Furneri, Eur J Med Chem, vol. 29, p. 781, 1994.

[4] L. Guofa, S. Tongshun, and Z. Yonghian, J Mol Struct, vol. 412, p. 75, 1997.

[5] A. K. Sutar, Y. Das, S. Pattnaik, A. Routaray, N. Nath, P. Rath, and T. Maharana, Chinese J Catal, vol. 35, p. 1701, 2014.

[6] K. C. Gupta and A. K. Sutar, Coord Chem Rev, vol. 252, p. 1420, 2008.

[7] K. C. Gupta and A. K. Sutar, J Mol Catal A: Chem, vol. 280, p. 173, 2008.

[8] A. K. Sutar, T. Maharana, Y. Das, and P. Rath, J Chem Sci, vol. 126, p. 1695, 2014.

[9] M. Vatankhah-Varnoosfaderani, S. Pourmahdian, and F. Afshar-Taromi, Iran. Polym J, vol. 20, p. 897, 2011.

[10] G. Grivani and A. Akherati, Inorg. Chem. Comm., vol. 28, p. 90, 2013.

[11] Q. H. Fan, Y. M. Li, and A. S. C. Chan., Chem Rev, vol. 102, p. 3385, 2002.

[12] A.F. Trindade, P. M. P. Gois, and C. A. M. Afonso, Chem Rev, vol. 109, p. $418,2009$.

[13] K. Ding and Y. Uozumi, Handbook of Asymmetric Heterogeneous Catalysis, Wiley-VCH, Weinheim, 2008.

[14] G. Ertl, Knozinger, H. F. Schuth, and J. Weitkamp, Handbook of Heterogeneous Catalysis, $2^{\text {nd }}$ edition, ch. 1-8, Wiley-VCH, Weinheim, 2008.

[15] J. Lu and T. H. Patrick, Chem Rev, vol. 109, p. 815, 2009.

[16] J. Escorihuela, L. González, B. Altava, M. I. Burguete, and S. V. Luis, Appl. Catal. A: Gen., vol. 462, p. 23, 2013.

[17] C. A. McNamara, M. J. Dixon, and M. Bradley, Chem Rev, vol. 102, p. 3275,2002

[18] S. L. Benjamin and K. Burgess, Chem Rev, vol. 103, p. 2457, 2003.

[19] N. Nath, A. Routaray, Y. Das, T. Maharana, and A. K. Sutar, Kinetics and Catalysis, vol. 56, p. 718-732, 2015.

[20] A. Syamal, D. Kumar, A. K. Singh, P. K. Gupta, Jaipal, and L. K. Sharma, Ind J Chem, vol. 41, p. 1385, 2002.

[21] R. L. Dutta and A. Syamal, Elements of Magnetochemistry, Sultan Chand \& Company Ltd., Ramnagar, New Delhi, 1982.

[22] R. Antony and G. L. Tembea, M. Ravindranathan, and R. N. Ramb, J Mol Catal A: Chem, vol. 171, p. 159, 2001. 
[23] J. C. Daram, Y. Jeannin, and L. M. Martin, Inorg Chem, vol. 19, p. 2935, 1980.

[24] R. C. Buijsman, E. Van Vuuren, and J. G. Sterrenburg, Org Lett, vol. 3, p. $3785,2001$.

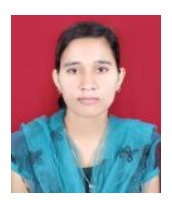

Nibedita Nath was born in Odisha, India, and obtained her B.Sc. in chemistry, M. Sc. in advanced organic chemistry and M.Phil in physical chemistry from Sambalpur University in 2005, 2007, and 2011 respectively. Presently, she is pursuing her Ph.D. degree in chemistry at Ravenshaw University under the supervision of Dr. Alekha Kumar Sutar in the area of polymer-supported catalysts. Her research interests include heterogeneous catalysts, the development of novel metal complexes for ROP of cyclic esters, and biodegradable polymers.

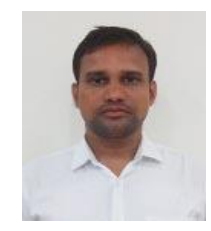

Harish Chandra Pradhan was born in Odisha, India, and obtained his B.Sc. in chemistry, M.Sc. in advanced inorganic chemistry and M.Phil in chemistry from Sambalpur University. Presently, he is pursuing his $\mathrm{Ph} . \mathrm{D}$. degree in chemistry at NIT Raipur under the supervision of Dr. Tungabidya Maharana in the area of polymer chemistry and Catalysis. His research interests include heterogeneous catalysts, the development of novel metal complexes for carbon dioxide sequestration, and biodegradable polymers.

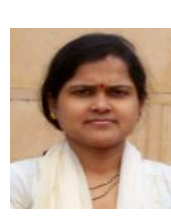

Tungabidya Maharana completed her Ph.D. degree at Indian Institute of Technology, Roorkee, under the supervision of Professor Y. S. Negi and Professor B. Mohanty, on polymer chemistry. She was a Lecturer at Ravenshaw University, India (2011-2013). She is continuing as an assistant professor at National Institute of Technology, Raipur, India since 2013. Her research interests include ring opening polymerization (ROP) of cyclic esters, copolymerization of carbon dioxide, biodegradable polymers by graft-copolymerization, polycondensation and ROP.

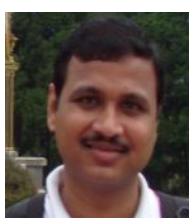

Alekha Kumar Sutar obtained his Ph.D. degree from Indian Institute of Technology, Roorkee on polymer supported catalysis. Then after he joined as Postdoctoral Fellow in the group of Prof. Chu-Chieh Lin at National Chung Hsing University, Taiwan. Currently he is working as Assistant Professor at Ravenshaw University, India. His main research interests include development of biocompatible and bioassimilable metal catalysts for the ring opening polymerization (ROP) of cyclic esters and copolymerization of carbon dioxide, polymer supported catalysis and biodegradable polymers. 